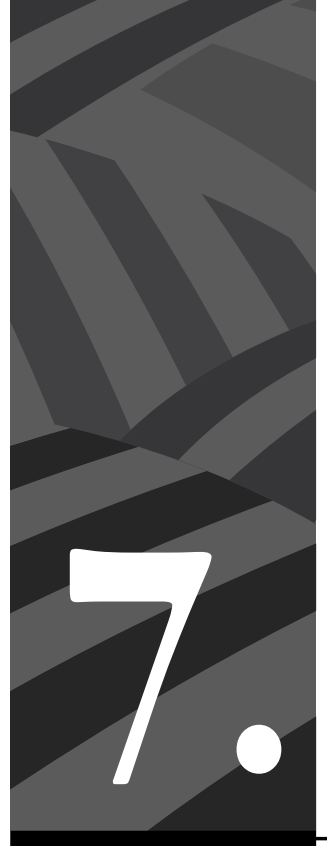

Apuntes para un cuidado inmanente y despersonalizado.

Entre la gestión del VIH

y la del SARS-CoV-2 


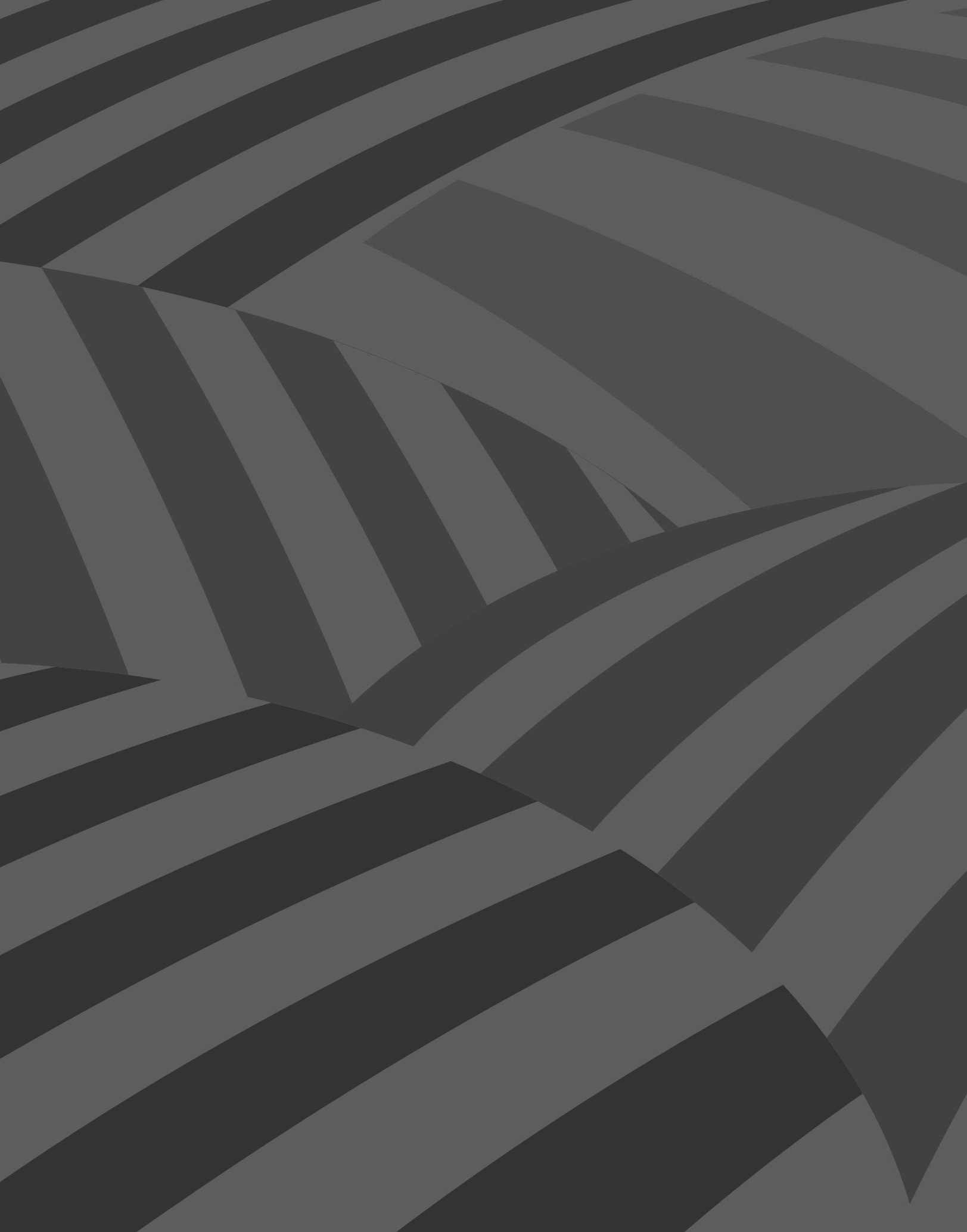




\title{
Apuntes para un cuidado inmanente y despersonalizado. \\ Entre la gestión del VIH y la del SARS-CoV-2
}

\author{
Por Jaime Sebastián Cancino Barreto
}

Resumen: En este artículo exploro la normalización del cuidado impulsada por la gestión de dos pandemias en Colombia: las provocadas por el VIH y el SARS-CoV-2. Paralelo a ello brindo elementos para un cuidado-otro que tiene como rasgos su inmanencia - que también nombro habitar- y su dimensión despersonalizada. Con esto en mente, rastreo los procedimientos mediante los cuales las instituciones estatales reclaman el monopolio de la gestión de estas pandemias; allí ahondo en la obediencia que solicitan y en el obstáculo que esto representa para el surgimiento de este cuidado-otro. Más adelante estudio lo que llamo "patologización del virus", explorando algunos de sus rasgos y los efectos políticos que traería, especialmente, la producción de un cuidado securitizado. Finalmente, me concentro en la alianza biopoder y capital, que cobra su mejor expresión en la disyuntiva "economía o vida" y que muestra que la protección biopolítica de la vida es también un hacer producir.

Palabras clave: biopoder, cuidado, capital, VIH, SARS-CoV-2.

\section{Notes for an immanent and depersonalized care. Between the management of HIV and of SARS-CoV-2}

Abstract: This article explores the normalization of care driven by the management of two epidemics in Colombia: HIV and SARS-CoV-2. Parallel to this, it provides elements for a different care that has and would have as traits its immanence - which I also name inhabiting - and its depersonalized dimension. To do this, I trace the procedures by which state institutions claim a monopoly on the management of epidemic; there, I delve into the particular obedience they request and the obstacle that this is to inhabit a different care. Later, I will stop at what I call "virus pathologization", exploring some of its features and the political effects it would bring, especially the building of securitized care. Finally, I will focus on the alliance between biopower and capital, which takes

* Politólogo y máster en Estudios Culturales de la Universidad Nacional de Colombia. Participante activo del grupo de investigación en Teoría Política Contemporánea (TEOPOCO) de la misma universidad. Línea de investigación: pensamiento político del sur. Correo electrónico: jscancinob@unal.edu.co 
its best expression in the famous dilemma "economy or life". That dilemma exposes that biopolitical protection life is a "make produce" too.

Keywords: biopower, capital, care, HIV, SARS-CoV-2 .

Cómo citar este artículo: Cancino Barreto, Jaime Sebastián (2020). Apuntes para un cuidado inmanente y despersonalizado. Entre la gestión del VIH y la del SARS-CoV-2. Revista Controversia, 216, 229-254.

Fecha de recepción: 2 de octubre de 2020.

Fecha de aprobación: 10 de noviembre de 2020.

\section{Introducción}

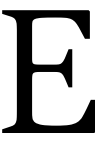

ste texto es, en parte, fruto de mi tesis en Estudios Culturales, donde examino la gestión del embarazo adolescente y de la epidemia de VIH por parte del Estado colombiano entre los años 2003 y 2018. El propósito en ese momento era problematizar políticas de salud pública que se mostraban a sí mismas neutras ética y políticamente. Al igual que allí, mi intención es problematizar la gestión de la epidemia SARS-CoV-2, para lo cual tomaré prestados algunos análisis que ya exploraba en la mencionada investigación y articularé esas indagaciones con algo que la "crisis" a la que asistimos ha mostrado agudamente: la normalización del cuidado. El objetivo de este artículo, entonces, es ahondar en esta normalización y, de paso, brindar algunos apuntes para otro cuidado posible, el cual tendría como precondición habitar los acontecimientos que estamos vivenciando. Para ello, primero, examino la manera en que las instituciones estatales/médicas buscan monopolizar la gestión de la crisis; aquí recurro a las exploraciones hechas en mi tesis y que se concentraron en los estudios del Ministerio de Salud y Protección Social (MSPS). En un segundo momento detallo cómo ello conduce a la "patologización del virus", que obstaculiza lo que yo llamaría un arte de la prudencia o del cuidado. Concluyo el artículo estudiando el surgimiento del afamado dilema entre "economía o vida", que vincula íntimamente las estrategias biorregulatorias con la reproducción del capital. 
Finalmente, antes de empezar brindo un breve contexto de mi investigación desarrollada en Estudios Culturales. Ella tomó como corpus los documentos producidos por el MSPS, que diseñaban las estrategias del Estado colombiano para regular la salud sexual y reproductiva de la población. Mi intención, luego, era hacer un estudio de archivo que me permitiera adentrarme en el discurso técnico del MSPS, para así mostrar, aunque se ocultase, su inexorable politicidad. Así las cosas, en algunas ocasiones haré uso de ese corpus, lo que me permitirá exponer las continuidades que rastreo en las dos gestiones.

\section{Entre la gestión del VIH y la del SARS-CoV-2}

Sorprenden los puentes que podemos tejer entre la administración de la pandemia del VIH y la del SARS-CoV-2. Empero, eludamos la tentación de ver la gestión de la última como la mera reproducción de dispositivos de poder anteriores. Si delineo puentes entre las dos, es también prestando atención a las mutaciones que acontecen.

Es conveniente, primero, abordar qué entiendo por biopolítica. Quizás las primeras puntadas de esta noción las podemos rastrear en Hannah Arendt (2005), quien veía que la Edad Moderna había convertido en públicas las labores que garantizan la supervivencia humana. Para ella, el orden público moderno, con el Estado como su mayor referente, sería ahora el encargado de resguardar la supervivencia de la especie. A este proceso Arendt lo nombró el auge de lo social, que según afirmaba mostraría la decadencia de la política actual y frente a la cual, sugerentemente, nos decía: "la sociedad de masas”, el estado más acabado de lo social, "en la que el hombre como animal social rige de manera suprema y donde en apariencia puede garantizarse a escala mundial la supervivencia de la especie, es capaz al mismo tiempo de llevar a la humanidad a su extinción” (Arendt, 2005, p. 56).

Desde una veta menos republicana, Michel Foucault es quien esgrime puntualmente el concepto y quien estudia con detenimiento algunos de 
sus rasgos, alimentados y complejizados luego por diversas posturas, especialmente feministas. En síntesis, por biopolítica Foucault (2002) entiende una tecnología de poder, surgida en Europa a finales del siglo XVIII y durante el siglo XIX, orientada a regular los fenómenos biológicos de las poblaciones. Para mostrar su singularidad, en sus clases -especialmente defender la sociedad y seguridad, territorio y población-, el autor francés delinea contrastes históricos con otras tecnologías de poder, las cuales, sin embargo, aún continuarían operando, ciertamente con menos fuerza. Así, mientras el poder soberano, proveniente de la Edad Media europea y que decae desde el siglo XVII, se caracteriza por el derecho a hacer morir, el biopoder se ocupa de los procesos biológicos de la población, es decir, pretende hacer vivir. A la gestión poblacional también la antecedió la anatomopolítica o poder disciplinar, que emergió durante el siglo XVIII y que está orientado a encerrar los cuerpos, a alinearlos, a hacerlos dóciles y, finalmente, a extraer de ellos el máximo de sus fuerzas. Las fábricas, escuelas, cárceles y hospitales son algunos de sus ejemplos. Así, si la anatomopolítica concentra su interés en los cuerpos individualizados y encerrados, el biopoder busca gestionar las grandes masas poblacionales que son cada vez más extensas con el auge del capitalismo. Al entrecruce de estas dos tecnologías Foucault lo llama sociedades de normalización, que, a diferencia del poder soberano que hace morir y deja vivir, se ocupan de la vida y buscan normalizarla. Con todo, y a pesar de la manera que lo expuse, vale repetir que para el famoso filósofo no hay una secuencia lineal entre diagramas de poder, como si uno desapareciera ante el advenimiento de otro; más bien, lo que cambia es el que domina y el uso que hace de los demás; por ejemplo, el biopoder traduciría el derecho a hacer morir en racismo de Estado, que es el mecanismo para dar muerte a los elementos biológicos peligrosos para la seguridad de la población. Este es, grosso modo, y a riesgo de simplificar, el concepto de biopoder trazado por Foucault.

Para mi estudio sobre la regulación del VIH en Colombia tomé prestado este análisis del biopoder, en especial porque me permitía historizar 
políticas de salud pública que se muestran a sí mismas neutras ética y políticamente, y necesarias para la buena salud de la población colombiana. También quise complejizar y enriquecer ese análisis desde lo que mostraba mi archivo de estudio, que ahora deseo ponerlo en relación con la gestión del SARS-CoV-2. Un primer asunto que saltó a la vista es el tono de alarma que habita en los documentos del MSPS sobre el VIH. Prestemos atención, por ejemplo, a un estudio recurrentemente citado que tuvo como objetivo brindar principios éticos y jurídicos para la gestión de dicha pandemia:

Este libro apoya la opinión de que la salud sexual y reproductiva es un tema no solamente legítimo, sino que exige la atención urgente de los profesionales de la salud y de sus aliados de otros campos que estén comprometidos con el logro de la salud individual y comunitaria en sociedades justas y humanas. (Cook, Dickens y Fathalla, 2003, p. 27).

Y el mismo documento, más abajo, afirma: "La salud [sexual] y reproductiva no es solamente un aspecto importante de la salud (...) Por razones de su impacto, urgencia e inequidad, es un asunto de interés global” (2003, p. 32). La anhelada neutralidad no deja de apelar a los sentimientos de cualquier lector: demandan urgencia, compromiso e interés global. Ese tono de alarma es extendido en todos los documentos que estudié, y en términos más generales se corresponde con un rasgo fundamental de estas políticas: la gestión de la pandemia del VIH mediante un ethos del miedo. Esto tiene su correlato en la búsqueda por producir sujetos con alta percepción de riesgo frente al VIH, esto es, sujetos que sientan el peligro de su propia sexualidad. De cualquier modo, para mi objetivo quisiera destacar que este uso del miedo viene de la mano con un reclamo de urgencia. El mismo documento del que extraje la anterior cita afirma:

Existen diferentes formas de definir la urgencia. En este contexto se utiliza para indicar un problema que empeorará mucho si hay demoras para atenderlo y que puede incluso volverse irreversible. De nuevo, este sentido de 
urgencia es claro en las áreas de regulación de la fecundidad y control de las ETS [enfermedades de transmisión sexual]. (Cook, et al., 2003, p. 38).

Esta sugerente definición brinda varios elementos para el presente análisis. Para empezar, la urgencia apelaría a una intervención sin demora, inmediata. Este primer rasgo, aunque lo extraigo de las políticas frente al VIH, permanece en la gestión del SARS-CoV-2. Por ejemplo, el 17 de marzo de 2020, cuando solo había 75 casos registrados en Colombia, la Alcaldía de Bogotá notificó la cuarentena en toda la ciudad, aludiendo a la necesidad de intervenir rápidamente la pandemia. Pocos días después el Gobierno nacional hizo lo mismo. Lo llamativo, para nuestro objetivo, es que este reclamo de inmediatez es también una apelación al automatismo: la respuesta inmediata es la respuesta automática, aquella preestablecida que surge mecánicamente y sin mediación —así lo sugiere el adjetivo inmediatez-. Esto se complementa con un segundo rasgo, quizás más llamativo, que también muestra esta última cita: si no se interviene rápidamente, el problema de salud pública podría empeorar dramáticamente, incluso hasta puntos irreversibles. En otras palabras, lo urgente no solo refiere a lo automático, sino además a que sin esta respuesta mecánica asistiríamos a escenarios catastróficos. Esta manera en la que se presenta la gestión del VIH, que se puede extender, como mostraré, a la del SARS-CoV-2, tiene implicaciones políticas relevantes: para eludir problemas “irreversibles", las estrategias biorregulatorias se muestran ineludibles, necesarias y, además, sin tiempo para ser mediadas. De modo que a la vez que reclaman urgencia, también solicitan el monopolio de lo que hay que hacer para atenderla. $\mathrm{O}$, en otras palabras, la urgencia es además un mecanismo a través del cual el biopoder se naturaliza.

Ahora bien, la alarma por el VIH provendría, entre otras cosas, de su cercanía a la muerte. Por ejemplo, el Plan Nacional de VIH 2008-2011, guía de las políticas estatales frente a dicha pandemia asevera: 
El VIH/Sida es una enfermedad con grandes repercusiones [...] que impone un reto para los sistemas de salud en el mundo. Desde el comienzo de la epidemia cerca de 60 millones de personas en el mundo se han infectado con el VIH y 25 millones han fallecido por Sida y causas relacionadas. (MSPS, 2014, p. 17).

Esta cita solo ejemplifica recurrentes descripciones que dejan ver la intranquilidad por la cercanía del VIH a la muerte. Estos planes nacionales repetidamente narran con alarma el aumento del contagio en el país y de la mortalidad que traería, y también la dificultad de producir una vacuna que contrarreste sus efectos negativos en la salud. Tal angustia por la muerte no es más que la protección de la vida mediante la exclusión permanente de ella, la muerte, sobre todo cuando el virus parece transmitirse mediante el contagio. Empero, la intranquilidad por el VIH no se agota allí. Prestemos atención, por ejemplo, a un documento que diagnostica la infección del VIH en el país desde la fecha del primer registro (1983) hasta el 2010:

De todas las enfermedades contagiosas, las enfermedades de transmisión sexual, incluyendo la infección de VIH, son las menos susceptibles de controlar erigiendo barreras nacionales. [...]

Por su naturaleza, ambos temas [las enfermedades de transmisión sexual y el VIH] constituyen un problema que no sólo continúa existiendo, sino que se multiplica. (Cook et. al., 2003, p. 38).

De esa manera, las enfermedades de transmisión sexual difícilmente serían controlables por las fronteras estatales, entre otras razones por su tendencia a multiplicarse. Las directrices internacionales para el control del VIH también manifiestan esta preocupación por su acelerado movimiento: "Durante esta década [1990], han sucedido muchas cosas [...] en relación con esta epidemia rápida y en constante evolución.” (Naciones Unidas, 2007, p. 4) [Cursiva mía]. Y luego de describir las acciones mundiales para regular la pandemia, como el aumento del 
uso de antirretrovirales, señala: “Sin embargo, la situación sigue siendo grave, con la duplicación del número de personas que viven con el VIH en el mundo y que supera los 40 millones” (2007, p. 5). La angustia que genera el VIH reside en que, además de arrastrar a la muerte, tendría un acelerado movimiento que lo hace difícilmente controlable. Es mediante este pavoroso panorama que las políticas del VIH reclaman para sí la urgencia de atender la pandemia: sin ellas aumentaría exponencialmente el contagio - poco control sobre el virus - y, concomitantemente, las muertes. El efecto naturalizante que arriba veíamos, según el cual el reclamo de urgencia también era la monopolización de lo que hay que hacer, parece concretarse en una disyuntiva: gestión del VIH o altas tasas de mortalidad. El correlato de este dilema es el estrecho espacio que estas políticas brindan para problematizarlas, pues ellas no aceptan mediación alguna si queremos esquivar tal panorama apocalíptico.

Los tiempos a los que asistimos parecen agudizar este dilema. Quizás el caso más ejemplar sea el giro autoritario que hemos presenciado durante la pandemia, que incluso parece alarmante para las mismas democracias liberales. La expedición masiva de decretos, que concentra los poderes del Estado en la Rama Ejecutiva y que para el caso de Colombia ha significado un excesivo presidencialismo, es solo una de sus expresiones. También hemos visto la suspensión de los derechos individuales y colectivos, que entre otras cosas condujo a una ambigüedad permanente frente al derecho a la protesta. Asimismo, presenciamos la militarización de las ciudades y la consecuente vulneración de los derechos por parte de la fuerza pública. Todo ello avanza junto a una tecnificación aguda de la política, en la que médicos y epidemiólogos cobran inusitada importancia y desplazan, parcialmente, la contingencia propia de lo político. En términos más foucaultianos, hay un uso biopolítico del poder soberano. En cualquier caso, para mi objetivo lo más llamativo es que este giro autoritario tiene hacedero en lo que llamé “efecto naturalizador del biopoder”, esto es, está justificado porque sería imprescindible para la protección de la especie humana. Y aunque luzca como un fenómeno coyuntural, este efecto naturalizador parece 
ahondarse en las formas de gobierno biopolítico, como es el caso del VIH.

Para el actual escenario, Amador Fernández-Savater (2020a) ha rastreado una disyuntiva similar a la que antes apuntábamos, aunque ciertamente recrudecida. Según este autor, no asistiríamos a una "gestión de la epidemia o altas tasas de mortalidad”, sino, más precisamente, a una "obediencia o fin del mundo". Esta nueva disyuntiva parece ser una buena manera para comprender el giro autoritario antes expuesto. En cualquier caso, el mismo autor sugiere, acertadamente, que este requerimiento de obediencia captura, a la vez, las posibilidades generativas que surgen de lo que estamos experimentando. Aquí me resulta oportuno tomar prestadas algunas reflexiones que la feminista Rosi Braidotti (2006) delinea frente a los acontecimientos, especialmente porque busca leerlos desde una veta posantropocéntrica. Según dice, por ellos podemos entender la radical interrupción en las condiciones de vida que cualquier individuo o colectividad puede experimentar por el simple hecho de vivir. Para ella, los acontecimientos son el resultado directo de los ciclos destructivos y generativos de la zoé, es decir, de lo que Occidente ha nombrado "vida natural”. Este acento en la zoé no es gratuito; antes bien, busca distanciar su perspectiva de visiones que ven a los acontecimientos como el producto de alguna voluntad humana, sea individual o colectiva. Por eso mismo su perspectiva ayuda a despersonalizarlos - no son el producto de alguien-, y frente a lo cual, siguiendo a Deleuze, asevera: "El sujeto libre, el sujeto ético, es el que tiene la capacidad de aferrarse a la libertad para despersonalizar el acontecimiento" (2006). Una lectura de este corte resulta profundamente nutritiva para los tiempos a los que asistimos: primero, permite distanciarnos de los juicios que atribuyen la pandemia a alguna voluntad, como aquellos que, por ejemplo, responsabilizan a científicos de Wuhan de fabricar el virus y de expandirlo con algún fin político o económico - por ejemplo, en varias ocasiones Donald Trump así lo manifestó-; segundo, también permite eludir la tentación de patologizar y culpabilizar el virus, como si fuese el responsable de los efectos 
destructivos que la pandemia ha traído sobre nuestras sociedades -en esto me detendré más adelante- Estos ejemplos serían dos formas distintas de personalizar el acontecimiento. En cambio, con Braidotti nos inclinamos a reflexionar sobre las condiciones históricas que hicieron posible los efectos devastadores que ahora vivenciamos, y no tanto por quién es el responsable.

Pero retomemos el hilo. Decía que todo acontecimiento es una interrupción radical en nuestras condiciones de vida. Por supuesto, esta interrupción trae efectos destructivos, y de ahí que puede acarrear buenas dosis de sufrimiento. La "monstruosa energía” de la zoé, nos dice Braidotti, "transforma y transpone y, por lo tanto, también destruye” (2006, p. 285). Es por su misma capacidad para descomponer que los acontecimientos también son instantes privilegiados para la creación de algo nuevo: ellos contienen el potencial para que el sujeto que los experimenta "lo[s] reelabore en relaciones positivas" (2006, p. 285). De ahí que para la filósofa italiana una relación éticamente positiva consista en ser capaz de extraer el potencial creativo que esta reserva. La disyuntiva “obediencia o fin del mundo” parece saturar, como sugiere Fernández-Savater (2020a), este potencial desatado por la pandemia: para su regulación se solicita de nosotros exhaustiva obediencia, lo que de paso obstaculiza las posibilidades creativas que cada persona, por el simple hecho de experimentar este acontecimiento, alberga. Si se quiere, la gestión de la pandemia originada por el virus SARS-CoV-2 requiere sujetos obedientes, no activos en la creación de nuevas maneras de vivir. Con todo, vale decir que lo que estamos experimentando siempre supera esa disyuntiva; el poder nunca es totalizante.

\section{Patologización del virus}

Ya dije que el temor al VIH provendría, por un lado, de su rápido movimiento que lo haría difícil de controlar y, por otro, de su intimidad con la muerte. La llegada del SARS-CoV-2 refuerza los rasgos de este temor, y al vivenciarlo en carne propia he podido observarlo desde otro 
punto de vista: parece de arraigo antropocéntrico, pues brota, primero, de la intranquilidad por la falta de control sobre el virus, esto es, sobre la Naturaleza, ${ }^{1}$ y, segundo, de la vulnerabilidad que esta ausencia de control desataría. Desde esta perspectiva podemos comprender mejor el tono apocalíptico que habita en los documentos sobre el VIH y que sentimos de nuevo con la llegada del SARS-CoV-2: refiere menos al "fin de la humanidad" que al temor por perder el control sobre la Naturaleza, especialmente cuando se exacerba, o al menos se muestra con mayor crudeza, nuestra interdependencia con ella. Como iremos viendo, este temor es quizás la primera puntada para mantener intactas nuestras sociedades, aun cuando las instituciones hayan impulsado algunos cambios.

En las políticas respecto al VIH este singular sentimiento desencadena en un uso particular de la ciencia. Prestemos atención a un documento del MSPS que caracteriza el VIH en Colombia desde la fecha del primer caso registrado (1983) hasta el 2010, y que fue publicado en el 2012:

La pandemia de Sida abrió nuevos retos para todo aquél [sic] interesado en el control de la infección por VIH, y generó múltiples investigaciones dirigidas hacia la generación de vacunas para evitar la infección o de productos farmacéuticos para controlar el virus o combatir sus efectos. (P. 83).

Este rico fragmento esclarece varios elementos sobre la manera como es concebido el VIH. Para empezar, vincula la ciencia -investigaciones, dice- con un reto particular: el control y combate del virus. Esto también viene acompañado, paradójica e implícitamente, de cierta actitud religiosa que deposita la esperanza en la ciencia para que controle el perverso virus. En ese momento no fue objetivo de mi investigación escrutar si esta fe desató, por parte del Estado colombiano o apoyadas

1 Para ser claro, no defiendo la dicotomía moderna entre humano y naturaleza, pues más bien veo las dos partes como totalidad. Sin embargo, mi posición no elimina el hecho de que tal dicotomía ha dado pie a la explotación y dominación moderna de lo no humano (Mies, 1997). De tal manera, cuando escribo Naturaleza con mayúscula es para referenciar y, a la vez, problematizar tal oposición. 
por él, investigaciones en esa dirección. Solo quise destacar esa esperanza en la ciencia, la cual parece extenderse e intensificarse con el acelerado movimiento del SARS-CoV-2. En este último caso, los Estados centrales han iniciado campañas empresariales e institucionales para fabricar la vacuna; y en el caso de los Estados periféricos, campañas diplomáticas para tener acceso a ella una vez esté creada. De cualquier manera, la esperanza en la ciencia reside en que sería el saber ideal para combatir y controlar el virus.

Vale precisar que, desde mi perspectiva, la ligazón entre religión y ciencia no es ilegítima, ni en el plano epistémico ni ético, aun cuando históricamente se haya querido ocultar — por ejemplo, las políticas frente al VIH, autodeclaradas como técnicas, recriminan repetidamente que la religión se entrometa en la sexualidad-; solo problematizo la manera como se apela a la esperanza y al saber científico. Para la fecha en que escribo este artículo (17 de septiembre de 2020) parecemos estar en un largo periodo de espera. ¿De qué? De un milagro de la ciencia que, con su capacidad para controlar y violentar, ${ }^{2}$ nos retorne a la antigua normalidad, o, diría yo, a la antigua normalización. Esa manera de cincelar estos dos saberes nos inmoviliza, primero, porque nos pone en espera -espera-nza - y, segundo, porque patologiza el virus: el problema es él, los efectos que tiene sobre nuestra biología y la dificultad para controlarlo, y no, por ejemplo, nuestras predatorias economías que, por el consumo masivo de unas pocas especies - las cuales, a la vez, las producimos en masa-, nos hace más propensos a las epidemias y pandemias. Y aquí el temor antropocéntrico, antes descrito, colabora para la espera y la patologización del virus: se le teme a algo "exterior” a nosotros, desconocido, imperceptible e ingobernable, lo cual nos invita, en últimas, a la gran guerra contra ese microorganismo.

2 En el actual contexto, este recurso a la violencia parece no solo ser metafórico. Ya algunas noticias han informado la "necesidad" de asesinar animales de especies que propagarían el virus, o, también, animales que serían necesarios para producir las tan anheladas vacunas. 
Desde luego, con esto no desconozco nuestra vulnerabilidad constitutiva, posición que estaría más cerca de perspectivas viriles que, por su lejanía con el cuidado, les cuesta reconocer nuestra vulnerabilidad y la atención que requiere. Esta es, en cambio, una invitación a atender nuestras fragilidades de una manera distinta y, sobre todo, a darles la importancia que ellas merecen. Siguiendo a Braidotti, me inclino por una postura más sensible al devenir de sí y de nuestras sociedades, que valore positivamente nuestra interdependencia mutua, tanto humana como no humana, y que por ello les otorgue la importancia merecida a nuestras vulnerabilidades; ella puede ser una perspectiva más justa, menos arrogante y más seductora. Mi inclinación hacia el devenir ayuda a eludir los juicios, sentencias y atribución de culpas que fustiga al virus y que le declara la guerra; más bien, traslada la atención hacia la crítica de sí y de nuestras sociedades que potencie el cambio. Braidotti ha sugerido que una perspectiva de esta índole tomaría distancia de moralizar los acontecimientos destructivos; ellos solo son el resultado de nuestra interacción con el mundo, con los cuales no estamos sintonizados. Patologizar el SARS-CoV-2 es otra manera de moralizarlo, y es a la vez la primera puntada para mantener intactas nuestras sociedades: el problema es cómo gestionar aquella entidad externa a nosotros, que parece ingobernable y que agudiza nuestra vulnerabilidad —es la idea moderna de lo salvaje-, lo cual elude la problematización de sí. Por supuesto las instituciones han propuesto cambios, pero solo para gestionar la crisis, no para transformaciones sustanciales del precario orden social y económico que rige. Por ejemplo, la pandemia ha exigido implementar rigurosas prácticas de prevención que permitan salir a trabajar; ello ha conducido a fuertes cambios en la cotidianidad, pero lo que parece incuestionable es el imperativo de productividad.

Para terminar este apartado quisiera, a modo de hipótesis y de apuesta ético-política, abrir caminos para la construcción de un cuidado mutuo que se distancie de la angustia o el temor. El escenario biopolítico que he trazado aquí transmite la sensación de que la única manera de cuidar es a través del miedo; de ahí que la gestión de la pandemia sea, 
ante todo, una administración de los riesgos. Esto mismo lo veíamos en el caso del VIH; allí, las políticas de salud pública buscaban inducir sujetos con alta percepción del riesgo, pues ello impulsaría y garantizaría el ejercicio del autocuidado. Lo llamativo, en estos dos casos, es que el miedo sería necesario para la autoprotección frente a un peligro biológico externo: sin ese afecto sería imposible el despliegue del cuidado. Frente a este uso del miedo vale la pena destacar, primero, que el cuidado queda reducido a un problema de seguridad y, segundo, que esta seguridad trazaría una frontera entre lo interno, lo que hay que proteger, y lo externo, aquello de lo que debemos separarnos y, en últimas, que debemos combatir si queremos protección. Luisa Fernanda Gómez, desde el psicoanálisis, ha avanzado en el estudio del odio en las sociedades contemporáneas, particularmente la colombiana. En su artículo "Apuntes para pensar la lógica del odio" (2019) destaca que este afecto nace de la lucha del yo por conservarse respecto a un Otro que lo desestabiliza. Así, para esta autora el odio sería la búsqueda por exterminar ese Otro diferente que problematiza la unidad del yo. El uso del miedo para promover el autocuidado parece estar a un paso de este odio, pues busca la protección frente a un peligro externo que, a pesar de todo, no parece tan identificable - puede ser cualquiera-. De ahí la retórica belicista contra el virus; pero también la aparición de actitudes xenófobas y de ataques violentos hacia los médicos, entre otras cosas. Solo faltaría agregar, complementando la perspectiva psicoanalítica, que estos afectos se ahondan en el gobierno biopolítico que escinde lo interno - el yo, mi familia, las poblaciones nacionales, etc. - de lo externo - el otro, el extranjero, etc.-.

Ante este impulso de un cuidado securitizado valdría la pena (re)crear y, por ende, (re)pensar el cuidado desde otras latitudes. Por mi parte, me inclino por uno que descanse en la alegría y el amor ${ }^{3}-y$ no en el miedo- por lo otro, por lo extraño - y no por lo propio-. La pregunta

3 El psicoanálisis considera a Eros como la pulsión por excelencia de la creatividad vital, que por supuesto excede el amor romántico. 
que abriría este camino sería: ¿Cómo cuidamos del otro, incluso, y sobre todo, en su radical diferencia? Aquí vale la pena echar mano, otra vez, de Braidotti (2006), quien delinea un sentido de la responsabilidad descentrada del yo y de lo propio. Para esta autora, la responsabilidad no está ligada al cumplimiento individual de normas, algo que en esta coyuntura se ha exacerbado y que ha cobrado el nombre de "ciudadano responsable”; por el contrario, pasa por estar atento al cuidado que toda existencia, humana y no humana, merece por el simple hecho de existir. De manera que el sujeto responsable no es quien cumple debidamente los deberes o las normas ciudadanas, sino quien, por su inexorable nexo con otros cuerpos humanos y no humanos, asume como propio el cuidado y, agrega esta autora, la potenciación de todo lo existente. Así, si el cuidado securitizado insiste en la escisión entre lo interno y externo, en esta perspectiva, que valga decir ya habita nuestras cotidianidades, se insiste en la ligadura con la diferencia. Por ejemplo, aquí los problemas ecológicos, sexuales, económicos, etc., de nuestras sociedades nos involucran a todos, y no solo a los gobiernos de paso o a las comunidades directamente implicadas. En las palabras de la filósofa italiana, "todos estamos juntos en esto".

(Re)crear el cuidado también debe pasar por despatologizar el daño, el peligro y los riesgos. Esto es de vital importancia si queremos construir un cuidado no securitizado, es decir, que no descanse en la seguridad como valor principal. En las políticas del VIH, como ahora, la patologización del daño cobra su mejor forma en la prevención, que no es otra cosa que los procedimientos que anticipan y pretenden evitar al máximo los peligros. En ese marco, el contagio, la enfermedad y la muerte son leídas como algo opuesto a la vida; de ahí que sean patologizadas y que inspiren miedo. Por mi parte, me inclino por darle el lugar adecuado a los daños. Desde luego, esto no se traduce en que los moralice positivamente, como si ellos intrínsecamente fuesen positivos. Braidotti, como dije, no oculta que los acontecimientos que nos descomponen traigan buenas dosis de sufrimiento; sin embargo, y de la mano de Nietzsche, asevera que para enfrentarlos requieren de amor fati, es 
decir, de la capacidad para reelaborarlos en relaciones alegres. Lo que me resulta interesante de esta propuesta es que la fidelidad del cuidado no debe estar del lado de la seguridad, sino, sobre todo, del lado de la buena vida, de la vida alegre. Y una vida de ese estilo requiere de experimentación, que es a su vez un abrirse a los peligros y a los daños.

Pero una ética de las pasiones alegres, como la que defiende Braidotti y que me interesa retomar acá, también pone atención a la sustentabilidad. Por eso, aunque despatologiza los daños, también está atenta a las fuerzas destructivas que pueden llegar a ser insostenibles. Para ella, la (in)sustentabilidad se podría comprender a través del concepto de límite, que marca "lo que un sujeto puede pensar/comprender/hacer/ devenir no más de lo que puede soportar o sustentar dentro de sus coordenadas temporoespaciales corporizadas” [cursiva mía] (2006, p. 286). Es la misma invitación que Deleuze y Guattari nos hacen al arte de la prudencia, que viene en íntima conexión con la experimentación:

$\mathrm{Al}$ conjunto de los estratos, el CsO [cuerpo sin órganos] opone la desarticulación (o las n articulaciones) como propiedad del plan de consistencia, la experimentación como operación en ese plano [...], el nomadismo como movimiento [...]. ¿Qué quiere decir desarticular, dejar de ser un organismo? Cómo explicar hasta qué punto es simple, y que lo hacemos a diario. Cuánta prudencia se necesita, el arte de las dosis, y el peligro, la sobredosis. No se puede andar a martillazos, sino con una lima muy fina [cursiva mía] (2015, p. 164).

Y más adelante continúa:

El CsO oscila constantemente entre las superficies que lo estratifican y el plan que lo libera. Liberadlo con un gesto demasiado violento, destruid los estratos sin prudencia, y os habréis matado vosotros mismos, hundido en un agujero negro o incluso arrastrado a una catástrofe [cursiva mía] (2015, p. 165). 
Estas bellas pero a veces empalagosas palabras solo nos instigan a estar atentos a las fuerzas que nos pueden arrojar a un "agujero negro" o arrastrar "a una catástrofe”. De ahí que pueda decir que un cuidado no securitizado y que esté orientado a alegrar la vida también estaría preocupado por la sustentabilidad humana y no humana. Esta prudencia-sustentabilidad es ante todo un arte, por lo cual no está dada de antemano, sino que depende de las "coordenadas temporoespaciales" de cada cuerpo y de la creatividad que de ahí surja. Así las cosas, si por un lado la gestión del SARS-CoV-2 buscó implementar normas universales para todos los ciudadanos, sin importar sus singularidades - de ahí que requiera obediencia-, al retomar estos dos autores me inclino por sujetos atentos a su situacionalidad y a lo que pueden hacer desde ahí. Mi invitación, si se quiere, es a que no seamos simples espectadores de lo que nos está pasando, sino a que logremos habitar esta interrupción, algo en lo que me detendré en las conclusiones.

Sin embargo, digámoslo otra vez, esta prudencia no privilegiaría la seguridad, sino más bien la experimentación y, por ende, una vida bien vivida. Desde esta perspectiva, por ejemplo, podemos comprender mejor las movilizaciones que han estallado en Colombia -especialmente en Bogotá, en el mes de septiembre-: desde un cuidado meramente securitizado, en ellas solo veríamos el aumento de riesgo epidemiológico; yo me inclino, en cambio, a interpretarlas como la defensa y, sobre todo, la apuesta por una vida que valga la pena ser vivida, lo que inclusive, como demuestran en parte las mismas movilizaciones, problematiza la extrema securitización de la cotidianidad —recordemos que estallaron por la violencia policial-.

Por su parte, lo que parece no tener prudencia es el capital. Aunque todo el escenario al que asistimos pareciera invitarnos a tomar una pausa $-\mathrm{y}$ en parte así ha sido, pues reducimos considerablemente nuestros encuentros con amistades y familiares-, rápidamente se nos hizo saber que el capital no podía parar. En esto me detendré en el próximo apartado. 


\section{Biopolítica y capital}

El 9 de mayo, más de un mes después de haber decretado la cuarentena en Colombia, el exministro y ahora rector de la Universidad de los Andes, Alejandro Gaviria, publicó una columna titulada "Los dilemas éticos de la pandemia" (2020). En ella, a la vez que reconocía que las cuarentenas fueron inevitables, señalaba que eran insostenibles por sus efectos económicos - en particular pobreza y hambre- y psicológicos. De manera que, aunque era tentador disminuir el riesgo a cero, solo alcanzado por la cuarentena estricta, proponía reaperturas prudentes, con ampliación en la cantidad de pruebas y volver a confinamiento cuando fuese necesario, es decir, cuando la capacidad hospitalaria estuviese al máximo. Lo llamativo de este escrito es que, a través de él, podemos rastrear distintas tecnologías de poder que operaron y operan en esta coyuntura y la que, al final de cuentas, vendría a dominar: como buen economista, el exministro privilegió la administración de los riesgos sobre perspectivas más rígidas que pretendían eliminarlos, es decir, ratificó la preponderancia de la biopolítica sobre poderes mucho más rígidos que solo prohíben.

Aunque esta columna fue fuertemente cuestionada, hasta el 28 de septiembre, fecha en la que escribo esta parte, es lo que ha predominado. A mediados de mayo empezaron algunas reaperturas controladas - aunque a veces no tanto, como los dos días sin IVA en los que los almacenes de cadena albergaron aglomeraciones-, que fueron luego acompañadas de cuarentenas sectorizadas según la zona de la ciudad, la urbe o la región del país. Estas cuarentenas han sido decretadas considerando distintas razones: la velocidad del contagio, la capacidad hospitalaria, la tasa de mortalidad, entre otras. Ya para finales de agosto, cuando la situación epidemiológica lo permitió, la Alcaldía de Bogotá y el Gobierno nacional impulsaron una reapertura mucha más extendida, que es lo que perdura hasta hoy, aunque con amenazas de un nuevo pico epidemiológico. Por supuesto, desde la primera reapertura económica, en mayo, aumentaron exponencialmente los contagios y las muertes, 
pero el objetivo, como bien lo mencionó Alejandro Gaviria, nunca fue reducir a cero los riesgos, sino gestionarlos, siempre precavidos de que los costos no fueran demasiados altos - por ejemplo, que el sistema de salud colapsara-. En otras palabras, asistimos a una auténtica biorregulación de la pandemia, que contrasta con los discursos de Donald Trump, Jair Bolsonaro o Andrés Manuel López Obrador, quienes repetidamente negaron el impacto de esta.

Como advirtió Foucault, el hacer vivir de la biopolítica viene de la mano de un dejar morir. La repentina llegada del SARS-CoV-2 ha visibilizado y agudizado este lado negativo de la biopolítica, y sus expresiones son variopintas: cuarentenas sin garantizar a todos(as) la vivienda, la alimentación y el sustento económico básico; el reposo sobre las capas menos privilegiadas de los "trabajos necesarios" que requieren de presencia física y, por ende, de mayor exposición al virus; el descuido generalizado y la infantilización de los "adultos mayores”, entre otros. Pero es quizás el surgimiento de la disyuntiva "economía o vida” la que devela cínicamente este dejar morir. Alejandro Gaviria, en la citada columna (2020), mostraba tal dilema: las estrictas cuarentenas eran insostenibles porque ampliaban y agudizaban la pobreza y el hambre; por lo tanto, era indispensable la reapertura económica. Pero ella, a su vez, arrastraría tasas de contagio y muerte más altas. El exministro era mesurado y reconocía allí un dilema ético, que solventaba recurriendo al viejo utilitarismo: realizar las acciones que menos sufrimiento provocarían, en este caso la reapertura prudente junto a la administración de los riesgos. Más de un mes después, el 20 de junio de 2020, el presidente Iván Duque era menos cauteloso y negaba el dilema: la reapertura sería la única opción posible, pues sin ella no habría manera de garantizar la vida - por ejemplo, no se podría asegurar el sostenimiento del sistema de salud-. En mis palabras, no podría haber vida por fuera de la economía: la economía es la vida misma. Por supuesto, cuando hablan de economía aluden a la contemporánea, es decir, al modo de producción capitalista. Y lo que parece permanecer, sea por el camino del exministro o por el del presidente, es lo inevitable de su funcionamiento. 
Esta aparente inevitabilidad de la economía no es otra cosa que la expresión misma del capital. Marx mostró agudamente cómo en el modo de producción capitalista la circulación y fabricación de mercancías no están orientadas a la satisfacción de necesidades de uso, sino fundamentalmente a la valorización indefinida del valor. Ello es así porque, según Marx, el dinero aquí no funciona como mecanismo para el intercambio de mercancías - el dinero para comprar lo que me hace falta-, sino que, ya convertido en capital, es el único objetivo de la circulación de ellas: vendo y compro no para satisfacer necesidades, sino para valorizar el dinero. A esto también le llamó "el flujo ininterrumpido de su renovación” (Marx, 2014, p. 523), que denota que el único fin del capital es su prolongación indefinida. Por ello mismo es que este autor nos dice que el capital se extiende permanentemente, conquistando nuevas capas de obreros y nuevos territorios, pues es la única manera que tiene para garantizar su valorización sin fin. Así las cosas, lo inevitable del funcionamiento económico, expuesto más arriba, no expresa tanto la imposibilidad de sostener modos de vida por fuera del capital - iacaso ya no hemos producido lo suficiente como para sostener la vida de todos? - como el intento por preservar los ciclos indefinidos de acumulación, parcialmente interrumpidos por la pandemia. Por ello mismo es que Fernández-Savater (2020b) asevera que el capital es extraterrestre, pues desconoce las cuestiones más mundanas. O, en términos más filosóficos, el capital solo busca trascender, en la medida en que pretende organizar la multiplicidad viviente en torno a él -incluso un virus-, sin mediar tiempo y espacio. De ahí su imprudencia e insustentabilidad.

Como insinué más arriba, lo anterior no puede comprenderse al margen del biopoder. Lo llamativo es que, como mostraba Alejandro Gaviria, la necesaria reapertura económica, que también es la reanudación de los ciclos de valorización del valor, exigía un despliegue de procedimientos que administraran los riesgos. Es decir, la protección de las poblaciones implicaba también la protección de sus capacidades para producir. Una de las formas que esto adquirió fue el impulso extendido de un autocuidado que permitiera la reapertura. Pero quizás su forma más acabada 
aparece, otra vez, en el ya mencionado discurso de Iván Duque: el dilema entre capital o vida sería falso, pues, desde esa perspectiva, no habría ninguna diferencia entre estos dos caminos. En mis palabras, la producción de la vida por el biopoder es también la producción de una vida al molde del hacer producir.

Ahora bien, a mi juicio el popular dilema no es como se muestra: quienes en las cuarentenas mueren de hambre son los sectores empobrecidos, y al tiempo son quienes deben salir a trabajar para no morir de inanición. La disyuntiva entre vida o economía se reduce a escoger los caminos por los que pueden morir las personas y grupos más vulnerables: de inanición o de la COVID-19. Con la reapertura se ha ido escogiendo la segunda vía. Y los mismos procedimientos que administran la muerte también registran la tendencia a concentrarla en los sectores populares. El Observatorio de Salud del distrito, para el 26 de julio consignaba 2196 muertes por COVID-19 en Bogotá; de ellas el 60\% se concentraban en los pobladores más empobrecidos de la ciudad -los estratos socioeconómicos 1 y 2-. Si a ello le agregamos el estrato socioeconómico que le sigue, considerado por el Departamento Administrativo Nacional de Estadística (Dane) como medio-bajo, las cifras rondarían el $84 \%$, esto es, 1836 muertes. Por su lado, los estratos más privilegiados, el 5 y 6 , solo aportaban 47 muertes, es decir, el 2,1\%. Más tarde, el 12 de agosto, la Universidad de los Andes registraba 24,9 muertes por cada 100000 habitantes de estrato 1 frente a 1,96 de estrato 6 (El Tiempo, 2020).

Pero dejemos de lado la seriedad de estos procedimientos que solo administran nuestras vulnerabilidades, y más bien detengámonos en asuntos más interesantes. En contraste con las políticas del VIH que examiné, aquí el dejar morir del biopoder aparece mucho más ligado al funcionamiento económico. Sayak Valencia (2012) ha llamado a esta complicidad "capitalismo gore", aunque ha puesto su atención en las economías ilícitas —narcotráfico, bandas criminales, explotación sexual, etc. La inesperada y abrupta llegada del SARS-CoV-2 subraya 
esta alianza, pero no desde las perseguidas ilegalidades, sino desde la administración institucional de los riesgos y de la muerte, que cobró la forma de capital o vida.

\section{Conclusiones}

A través de estas palabras simplemente los he querido invitar a que habitemos juntos lo que nos está pasando. La expresión "habitar" la tomo, otra vez, de Amador Fernández-Savater (2020c), quien con palabras justas nos dice:

Habitar la situación, no dejarse simplemente gestionar. ¿Qué significa? Poblar la situación de nuestras preguntas, nuestros pensamientos, nuestras necesidades, nuestros deseos, nuestros saberes, nuestras redes de afecto.

Habitar, estar presentes, no ser sólo espectadores o consumidores o víctimas de las decisiones de otros, sino sentir, pensar y crear a partir de lo que pasa, darle valor, compartirlo, hacer con ello mundo y vida.

La primera puntada para ello era lograr problematizar los procedimientos que reclaman para sí el monopolio de lo que se debe hacer y pensar; en mi estudio esto cobró la forma de gestión de la pandemia o muerte. Más allá de esto, mi invitación es para que cada cuerpo, desde su situacionalidad singular, logre "poblar" sus propias experiencias, y no ser, como dice Fernández-Savater, meras víctimas de las decisiones de otros. Por ejemplo, la llegada del coronavirus y las consecuentes cuarentenas han abierto realidades menos aceleradas, en particular con relación a las formas predatorias de consumo. ¿Cómo lograr afianzar esas nuevas realidades si no es habitando nuestras propias vivencias, "creando a partir de lo que nos pasa”? Los poderes, por su parte, solo pretenden gestionar la crisis, y por ello están a la espera del retorno de la antigua normalidad, es decir, en este caso, de nuestro rapaz consumo. También, por ejemplo, para muchas personas el "aislamiento social” ha significado fuertes sufrimientos psíquicos; allí se pueden abrir nuevos juegos de 
preguntas —qué es lo que me genera sufrimiento, por qué, cómo impulsar transformaciones de aquello, etc.-, pero es indispensable habitar lo que nos está pasando. Aquí el peligro es ver estos sufrimientos como problemas médicos, lo que a la postre, otra vez, deshabilitaría el impulso por habitarlos. Estos solo son algunos ejemplos de las múltiples vivencias a las que asistimos; lo indispensable, creo, es lograr conectar nuestras experiencias singulares con condiciones históricas de más largo aliento. El movimiento feminista es quizás el que más ha insistido en ello, al ser enfático en que lo personal es político.

\section{Referencias}

Arendt, Hannah. (2005). La condición humana. Buenos Aires: Paidós.

Braidotti, Rosi. (2006). Transposiciones. Sobre la ética nómada. Barcelona: Gedisa.

Cook, Rebecca; Dickens, Bernard y Fathalla, Mahmoud. (2003). Salud reproductiva y derechos humanos. Integración de la medicina, la ética y el derecho. Bogotá: Asociación Probienestar de la Familia Colombiana [Profamilia]. Recuperado el 16 de octubre de 2018 de https://www.law.utoronto. ca/utfl_file/count/documents/reprohealth/rh_hr_spanish.pdf

Deleuze, Guilles y Guattari, Félix. (2015). Mil mesetas. Capitalismo y esquizofrenia. Valencia: Pre-Textos.

Estratos bajos en Bogotá sienten con más rigor los efectos de la COVID. (13 de agosto de 2020). El Tiempo. Recuperado de https://www.eltiempo.com/ salud/impacto-de-la-COVID-19-en-los-estratos-de-bogota-los-mas-bajosson-los-que-mas-sufren-528738

Fernández-Savater, Amador. (22 de mayo de 2020a). Obediencia o fin del mundo: la estrategia de disuasión. Recuperado el 2 de julio de 2020 de http:// lobosuelto.com/obediencia-estrategia-de-disuasion-fernandez-savater/

Fernández-Savater, Amador. (1 de agosto de 2020b). Terrícolas contra humanos ¿Por qué no podemos parar? Recuperado el 9 de septiembre de 2020 de http://lobosuelto.com/terricolas-contra-humanos-por-que-no-podemosparar-amador-fernandez-savater/ 
Fernández-Savater, Amador. (16 de marzo de 2020c). Habitar la excepción: pensamientos sin cuarentena. Recuperado de http://lobosuelto.com/ cuarentena-amador-savater/

Foucault, Michel. (2002). Defender la sociedad. México D.F.: Fondo de Cultura Económica.

Gaviria, Alejandro. (9 de mayo de 2020). Los dilemas éticos de la pandemia. El Tiempo. Recuperado de https://www.eltiempo.com/lecturas-dominicales/ rector-de-la-universidad-de-los-andes-alejandro-gaviria-reflexiona-sobrela-pandemia-493500

Gómez Lozano, Luisa Fernanda. (2019). Apuntes para pensar la lógica del odio. Desde el Jardín de Freud, (19), 263-269.

Marx, Karl. (2014). El capital. Crítica de la economía política. Tomo I. México D.F.: Fondo de Cultura Económica.

Mies, María. (1997). Investigación feminista, ciencia, violencia y responsabilidad. En Vandana Shiva y María Mies, Ecofeminismo. Teoría, crítica y perspectivas (pp. 59-81). Barcelona: Icaria Editorial.

Ministerio de Salud y Protección Social. (2012). Panorama del VIH/Sida en Colombia. 1983-2010. Recuperado el 3 de diciembre de 2018 de https:// colombia.unfpa.org/sites/default/files/pub-pdf/PANORAMA-VIH-SIDACOLOMBIA-1983-2010.pdf

Ministerio de Salud y Protección Social. (2014). Plan Nacional de Respuesta ante ITS-VIH/Sida (2014-2017). Recuperado el 28 de octubre de 2018 de https://www.minsalud.gov.co/sites/rid/Lists/BibliotecaDigital/RIDE/VS/ PP/plan-nacional-respuesta-its-2014-2017.pdf

Naciones Unidas. (2007). Directrices internacionales sobre el VIH/SIDA y los derechos humanos. Versión consolidada de 2006. Recuperado de http://data. unaids.org/pub/report/2006/jc1252-internationalguidelines_es.pdf

Valencia, Sayak. (2012). Capitalismo Gore y necropolítica en México contemporáneo. Relaciones Internacionales, (19), 83-102. 